\title{
Influence of Hub Parameters on Joining Forces and Torque Transmission Output of Plastically-Joined Shaft-Hub-Connections with a Knurled Contact Surface
}

\author{
Lukáš Suchý ${ }^{1, *}$, Erhard Leidich ${ }^{1}$, Thoralf Gerstmann ${ }^{2}$ (1) and Birgit Awiszus ${ }^{2}$ \\ 1 Professorship Engineering Design, Institute of Design Engineering and Drive Technology, \\ Technische Universität Chemnitz, 09126 Chemnitz, Germany; erhard.leidich@mb.tu-chemnitz.de \\ 2 Professorship Virtual Production Engineering, Institute for Machine Tools and Production Processes, \\ Technische Universität Chemnitz, 09126 Chemnitz, Germany; thoralf.gerstmann@mb.tu-chemnitz.de (T.G.); \\ birgit.awiszus@mb.tu-chemnitz.de (B.A.) \\ * Correspondence: lukas.suchy@mb.tu-chemnitz.de; Tel.: +49-371-531-32446
}

Received: 27 February 2018; Accepted: 4 April 2018; Published: 9 April 2018

\begin{abstract}
A knurled interference fit is a machine part connection made by a plastic joining, which includes the advantages of commonly-used shaft-hub-connections. The combination of the friction and form fit, which are responsible for torque transmission, results in a higher power density than conventional connections. In this paper, parameter gaps are bridged with the aim of enhance the design calculation of the knurled interference fit. Experimental investigations on the shaft chamfer angle (100Cr6) and hub-diameter-ratio (AlSi1MgMn) were performed. The analytical approaches are developed for calculating the joining force and maximal torque capacity by accounting for experimentally investigated loss of load transmission at high hub-diameter-ratios and high shaft chamfer angles. The presented calculation approach is an accurate tool for the assessment of early machine designs of the knurled interference fit and helps to save from having to perform time-extensive tests.
\end{abstract}

Keywords: knurled interference fit; shaft-hub-connection; joining by plastic forming; torque capacity; joining force; drive train

\section{Introduction}

Turning drives are commonly used and important actuators in machines. Several principles for transmitting rotatory drive torque through machine parts from the source of power to the output side are established. Well-known principles are the key fit joint or the splined shaft fit, which belong to the group of so-called "positive fits" or "form fits". By contrast, the interference fit ("non-positive fit" or "friction fit"), where an oversized cylindrical shaft is pressed into the undersized cylindrical hub, transmits torque by joint pressure and is used in numerous applications, such as train axles. Combining these two well-known joining methods enables assembly of a splined shaft and hub with a cylindrical hole by axial plastic forming, bringing together the advantages of both principles and increasing the maximal transmissible torque (Figure 1). This so-called knurled interference fit (KIF) is fabricated by axial pressing the knurled shaft into a slightly undersized hole in the softer hub. The plastic forming of the counter profile in the hub eliminates tolerance errors and guarantees a homogenous force distribution over all tappets during operation. Furthermore, axial loads can be transmitted by the groove pressure in the connection. 
The joining process of well-known interference push-in-connection can be estimated both according to the German standard for calculating interference fit DIN 7190 [1] as well as numerical methods from several investigations (e.g., [2,3]). In contrast to this investigation dealing global elastic-plastic relations with low deformation degree, a KIF connection is formed mainly locally at the contact groove with very high local deformation. Therefore the joining process of KIF cannot be reproduced with the presented methods.

In contrast to the conventional interference fit, the groove pressure decreasing separation frequency [4] in high-speed applications does not lead to transmission break down due to the form fit of the tappets. The knurl profile is understood according to German standard DIN 82 [5].

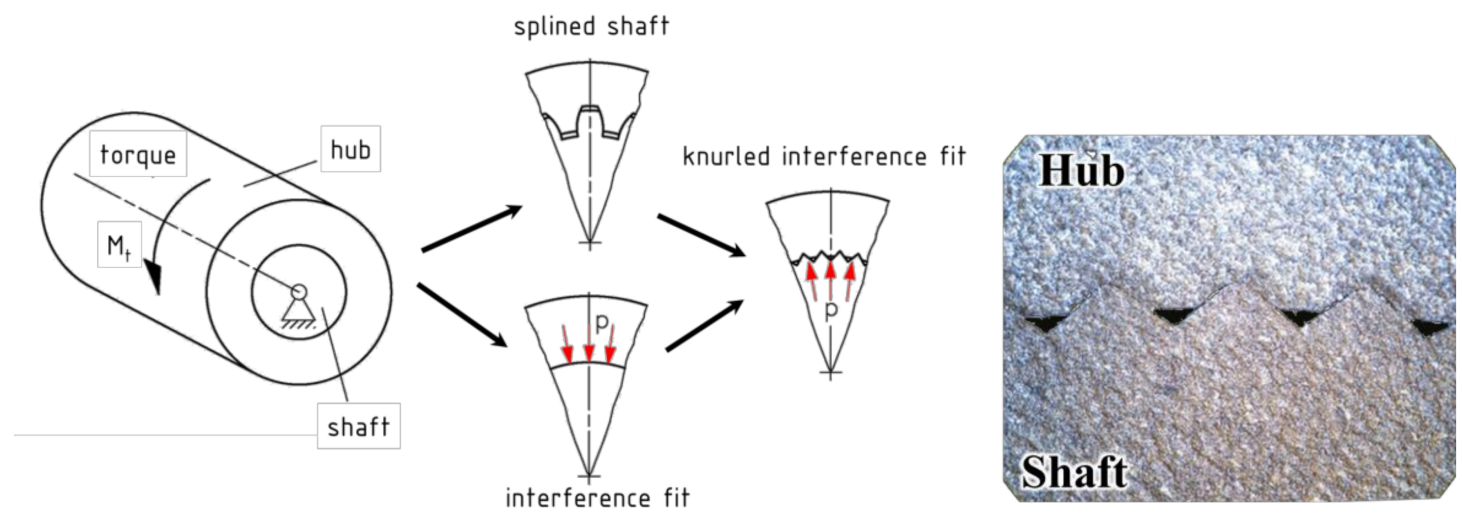

(a)
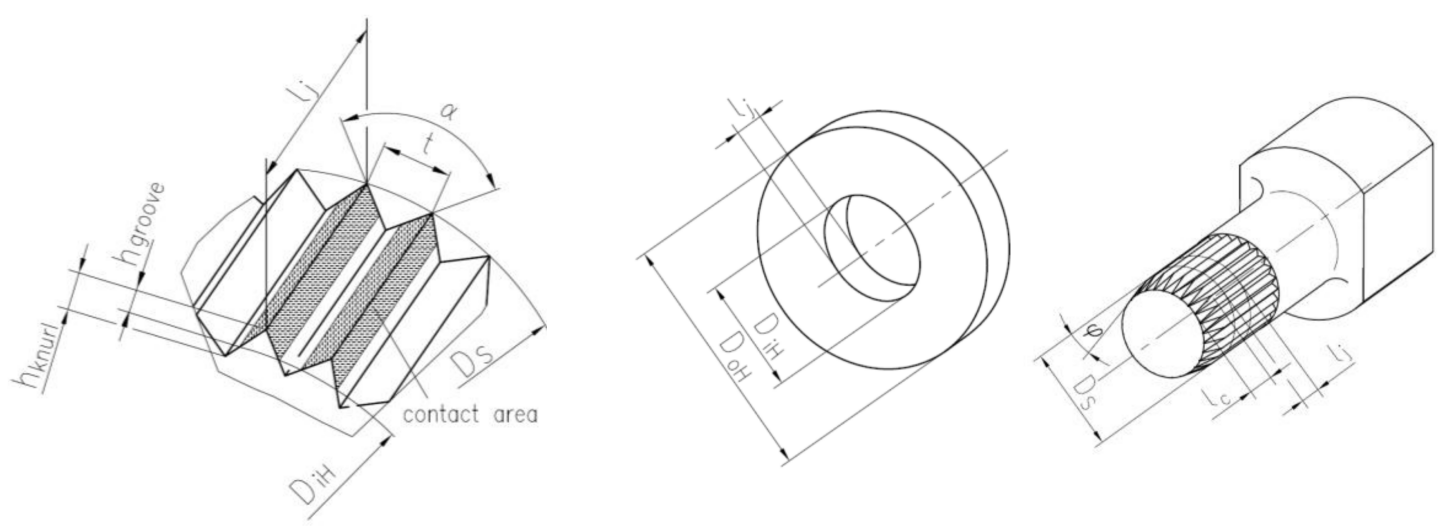

(b)

Figure 1. (a) Fusing of principles for torque transmission; and (b) geometry of knurled interference fit according to [5].

Equations describing this joint were recently published. Extensive recent overviews of past research can be found in [6-8], where the joining process and torsional load capacity are investigated. Nonetheless, the state of the knowledge is not sufficient for design of a universal KIF for a broad range of applications. Additionally, the valid patents in Europe lack detailed instructions for design and scientific explanations.

Lätzer [6] recently described the influence of different geometric parameters on joining and operating behavior, including important consequences of joining by cutting and forming. Fits joined by forming with shaft chamfer angles (SCA) $\phi<60^{\circ}$ are able to transmit $40 \%$ more torque than fits joined by cutting, where $\phi=90^{\circ}$. Additionally, an analytical approach for designing KIF based on 
operational state is introduced. Equations (1) and (2) shows Lätzer's approach [6] for estimation of necessary joining force and maximal transmittable torque:

$$
\begin{gathered}
T_{\tau_{s}}=D_{S} / 2 \cdot t \cdot l_{j} \cdot i \cdot \tau_{S}\left(\varepsilon_{K I F}^{p l}\right) \\
F_{J}=A_{\text {contact }} \cdot \mu \cdot p\left(\varepsilon_{K I F}^{p l}\right) \cdot K_{Q H}
\end{gathered}
$$

With the exception of the hub-diameter-ratio (HDR), this formulation includes the geometry parameters of KIF (Figure 1). The terms $\tau_{S}\left(\varepsilon_{K I F}^{p l}\right)$ and $p\left(\varepsilon_{K I F}^{p l}\right)$, the equivalent plastic strain and the strain hardening, can be calculated by the Ludwik approach. Additionally, differentiation between the cutting and forming joining methods is performed. The results of this study are valid only for thick walled hubs of ductile aluminum material. The value of the hub-diameter ratio is the thickness rate of the hub and can be calculated for steady hub outer diameters using Equation (3):

$$
Q_{H}=\frac{D_{i H}}{D_{o H}}
$$

The interference $I_{g e o}$ is the difference between the shaft diameter $D_{S}$ and the hub diameter $D_{i H}$ :

$$
I_{\text {geo }}=D_{S}-D_{i H}
$$

Bader investigated the self-cutting knurling shaft-hub-connection [9] and determined the necessary hardness-ratio of the hub and shaft, which is calculated from different combinations of steel, brass, and aluminum. The minimal hardness ratio was 1.8. Furthermore, the first applicable empirical approaches were derived, but they lacked the universal validity for forming KIF.

Against this background, the central question that motivates the present research is the influence of other parameters on the maximal transmittable torque of the knurled interference fit, such as the hub thickness in combination with the shaft chamfer angle.

Further studies investigate forming KIF connections with different, and not standardized, geometries and tappet orientations [8]. Similar increasing load capacity tendencies were recorded in dependence of growing interference. Due to high influence of the different tappet geometry on the plastic forming during joining process, the quantitative comparability is not possible. Additionally, the shape development of the tappets is not introduced.

The lack of complete investigations on the influence of hub outside-diameter on joining and torsional load force make this research necessary. The loss of stiffness of thin walled hubs will change the maximal possible load capacity of the KIF. The validity condition of this statement is the failure of the knurls.

First, experiments investigating joining and operating state are performed. The present analytical approaches will then be extended.

Table 1 shows the parameters that influence joining forces and maximal transmittable torsional load in the design of a KIF. The most important factors are the shaft diameter, the joining length, and the geometric interference (Figure 1). 
Table 1. Parameters that influence knurled interference fits: $\nearrow$ represents a larger influence with an increasing parameter; $\searrow$ represents an opposed influence with an increasing parameter, ( ) represents a hypothesized influence.

\begin{tabular}{ccccc}
\hline Parameter (Increasing) & Symbol & Influence on Maximal Joining Force & Influence on Maximal Torque \\
\hline Shaft diameter & $\nearrow$ & $D_{S}$ & $\nearrow$ & $\nearrow$ \\
Hub outer-diameter & $\nearrow$ & $D_{o H}$ & $(\nearrow)$ & $(\nearrow)$ \\
Joining length & $\nearrow$ & $l_{j}$ & $\nearrow$ & $\nearrow$ \\
Shaft chamfer angle (SCA) & $\nearrow$ & $\phi$ & $\searrow$ & $\searrow$ \\
Geometric interference & $\nearrow$ & $I_{g e o}$ & $(\searrow)$ & $(\searrow)$ \\
Hub-diameter ratio (HDR) & $\nearrow$ & $Q_{H}$ & & $\nearrow$ \\
\hline
\end{tabular}

\section{Materials and Methods}

Investigations on hub outside-diameter are performed on specimens with flange geometries as shown in Figure 2. The figured hub specimens are manufactured from rods of AlMgSi1, EN AW-6082, with heat treatment T6. The shaft material is bearing steel 100Cr6. The basic shaft geometry is manufactured in the untreated state. Subsequently, the knurling is fabricated on the specimen by recursive axial forming. Finally, the specimen is hardened to a hardness of approximately $758 \mathrm{HV}$. The resulting hardness ratio of joined specimens is 1:7 (Table 2).

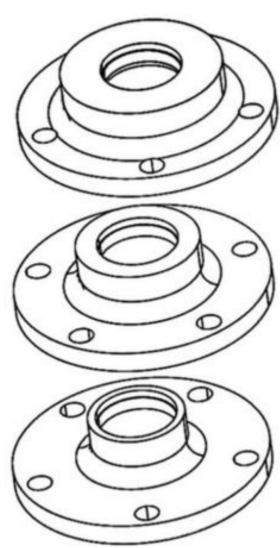

(a)
$Q_{H}$

0.50

0.65

0.83

\begin{tabular}{l|l} 
Parameter & Value \\
\hline Shaft diameter $D_{s}$ & $30 \mathrm{~mm}$ \\
Hub-diameter ratio $Q_{H}$ & $0.83,0.65,0.50$ \\
Joining length $l_{j}$ & $6 \mathrm{~mm}$ \\
Shaft chamfer angle $\phi$ & $5^{\circ}, 45^{\circ}, 90^{\circ}$ \\
Groove/knurl angle $\alpha$ & $103^{\circ}$ \\
Pitch $t$ & $1 \mathrm{~mm}$ \\
Geometric interference $I_{g e o}$ & $t^{*} 2 / 3$
\end{tabular}

(c)

Figure 2. (a) Aluminum hub, forging alloy AlMgSi1; (b) steel knurled shaft bearing steel 100Cr6; and (c) experimental parameters.

Table 2. Material properties.

\begin{tabular}{ccccc}
\hline & Yield Stress $\boldsymbol{R}_{\mathbf{p} \mathbf{0 . 0 2}}$ in MPa & Tensile Strength in MPa & Rupture Strain in \% & Hardness \\
\hline AlMgSi1 & 309 & 340 & 7.3 & $105 \mathrm{HV} 10$ \\
100Cr6 & & $2525^{*}$ & $758 \mathrm{HV} 1$ \\
\hline \multicolumn{4}{c}{$*$ calculated from hardness [6] }
\end{tabular}

* calculated from hardness [6].

Figure 2 shows the specimen geometry as well as the chosen parameter values for the present study. The influence of different hub-diameter-ratios $Q_{H}$ on joining forces and maximal torque capacity differed by cutting and forming joining method is examined by varying the shaft chamfer angle $\phi$ for each HDR.

The joining process is performed in a special guiding appliance that guarantees the coaxial position of hub and shaft during the assembly in hydraulic press. The joining velocity $v_{j}$ was $0.5 \mathrm{~mm} / \mathrm{s}$ due to comparability within the presented literature. The surfaces were cleaned before a dry joining process. The maximal joining force is derived from the gained force-stroke-signal. 
After a one-day rest period the assembled connection is tested in a hydraulic torsional test bench, where the torque progression over the torque angle is measured until the failure of KIF occurs (stress-controlled test). At this value, the maximal torque capacity is obtained.

Material properties (Table 2) were estimated in tensile testing according to ISO 6892 [10] for the hub material AlMgSi1. In the case of the hardened steel shaft the hardness was measured according to ISO 6507 [11] and the tensile strength was calculated according to [6]. All tests were performed at room temperature.

\section{Results}

\subsection{Experimental Results}

Joining force plots shown in Figure 3a summarize the maximal forces of tested specimens. Every point represents a mean value of two repetitions with a maximal standard deviation of maximally $3.4 \%$ (joining force) and $2.9 \%$ (torque), respectively. At the lower HDRs of $Q_{H}=0.65$ and $Q_{H}=0.5$, the maximum joining force increases with decreasing SCA, peaking at $\alpha=5^{\circ} .12 \%$ lower values for $Q_{H}=0.65$ are observed at this point.

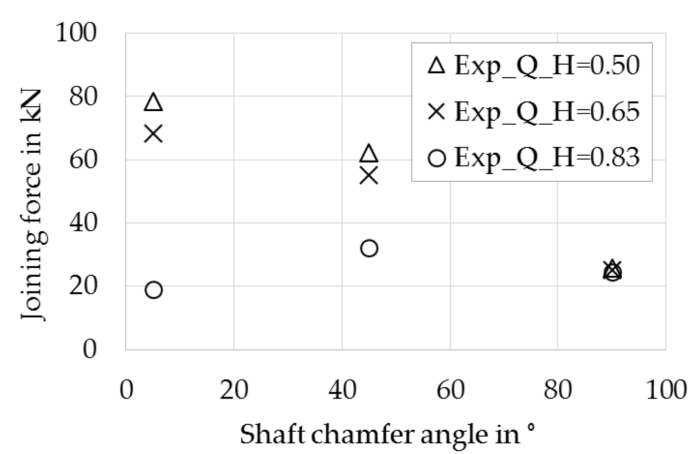

(a)

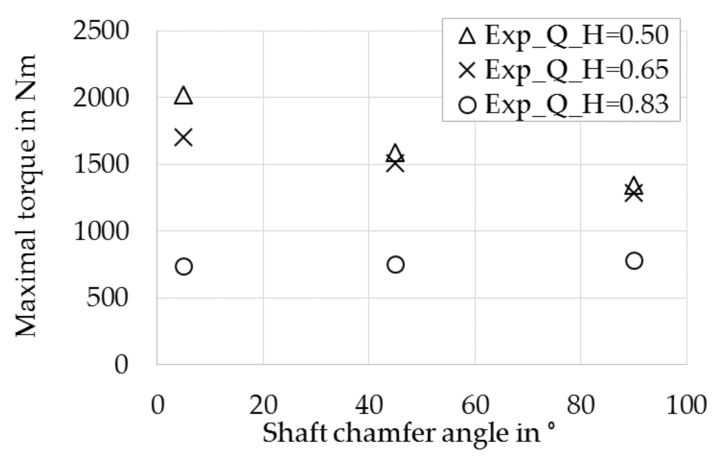

(b)

Figure 3. Results from hub-diameter ratio and shaft chamfer angle testing, (a) maximum joining force; and (b) maximal torque capacity.

In contrast, the thin walled hub with $Q_{H}=0.83$ shows a plateau at lower joining forces. While all HDR forces are the same at $\alpha=90^{\circ}$, values diverge nonlinearly with decreasing SCA.

The forming process causes redirection of the axial force to a hub-expending radial force, which results in higher groove pressure and higher joining forces than the cutting process for hubs with higher wall thicknesses. In contrast, the thin walled hub does not show this effect due to high hub expansion during joining and the related lower plastic deformation and shorter height of teeth in the hub. The joining forces of forming KIF are about $20 \%$ lower than for cutting KIF.

Figure $3 b$ shows the corresponding maximal torsional load, which is the load where the KIF fails. Similar trends of joining force (Figure 3a) can be observed. Except for the thin-walled hub, where the values at the plateau are lower, the forming connection also achieves a higher maximal torque. The higher torque capacity of forming KIF is rationalized by strain hardening of the ductile material AlMgSi1.

Additionally, the maximal torsional load of a thin walled $\operatorname{KIF} Q_{H}=0.83$ joined by cutting $\left(\alpha=90^{\circ}\right)$ is about $40 \%$ lower than KIF with $Q_{H}=0.5$ and $Q_{H}=0.65$. This difference can be explained by radial expansion of the hub caused by the torque applied during testing. Enlargement of the hub inner diameter, caused by the force split of the torque on the sloping side of the formed/cut knurling, leads to decreased contact area. Interrelated reduction of the teeth shear area results in a smaller torque capacity for the hub with thin walls with $Q_{H}=0.83$. 


\subsection{Analytical Approach for Calculation of Joining Force and Torque Capacity}

The following description involves including the tested parameter in the available calculation method, thereby expanding the approach of Lätzer.

The first set of analysis highlights the impact of HDR on the formation of the counter profile in the hub. Figure 4 shows the different groove heights $h_{\text {groove }}$ dependency on SCA and HDR. The green area represents the neglected area in the field of thin hub and forming joining process. At this point, the contact area is reduced as a result of radial hub expansion.

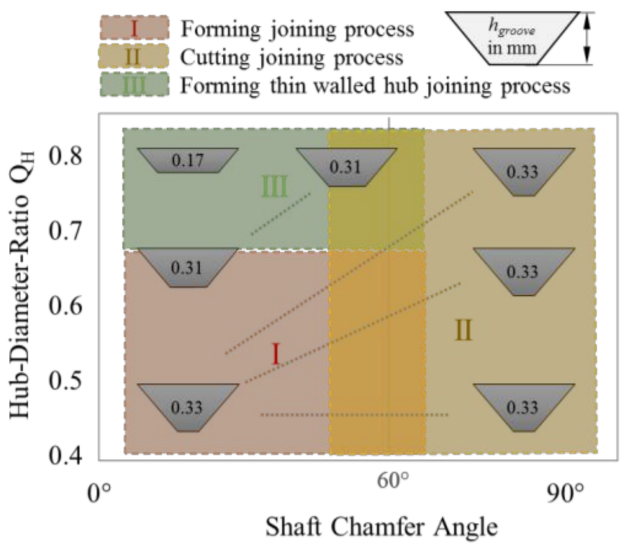

(a)

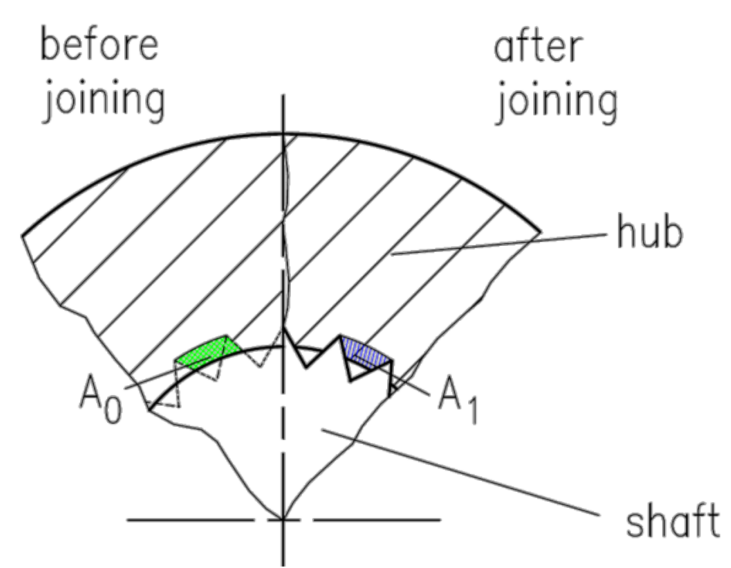

(b)

Figure 4. (a) Hub groove height formation after KIF joining; and (b) calculation areas for equivalent plastic strain $\varepsilon_{R P V}^{p l}$.

When low radial forces are initiated in the cutting process, groove formation is due to material removal resulting in equal groove heights (Figure $4 \mathrm{a}$, yellow area).

Knurl forming on the thick hub, which is at lower HDR, leads to constant groove heights. In contrast to the cutting process, the material undergoes strain hardening, which is calculated in Equations (5) and (6) in the equivalent plastic strain term $\varepsilon_{K I F}^{p l}$.

The intersection of the described areas border the crossing parameter area, where the joining processes are mixed.

In addition to Lätzer's approach, the following equations are used for calculation of joining force $F_{J}$ and maximum torque $T_{\text {torque,max }}$ considering the tested parameters:

$$
\begin{gathered}
F_{J}=A_{\text {contact }} \cdot \mu \cdot p\left(\varepsilon_{K I F}^{p l}\right) \cdot K_{J} \\
T_{\text {torque,max }}=\left(\frac{D_{S}}{2}-h_{\text {groove }}\left(Q_{H}\right)\right) \cdot l_{j} \cdot i \cdot t \cdot \tau_{S}\left(\varepsilon_{K I F}^{p l}\right) \cdot K_{T}
\end{gathered}
$$

Here the coefficient of friction $\mu$ is determined by a standardized tube friction method from [12]. The groove pressure $p\left(\varepsilon_{R P V}^{p l}\right)$ is calculated according to [6] to be equal to the flow stress $k_{f}\left(\varepsilon^{p l}\right)$.

The modification to the original Lätzer approach [6] consists of new reference areas $A_{0}$ and $A_{1}$ for calculation of equivalent plastic strain $\varepsilon_{R P V}^{p l}$, which is defined as:

$$
\begin{aligned}
& \varepsilon_{K I F}^{p l}=\left|\ln \left(\frac{A_{1}}{A_{0}}\right)\right| \\
& \mathrm{A}_{0}=t \cdot h_{\text {groove }}\left(Q_{H}\right)
\end{aligned}
$$




$$
\mathrm{A}_{1}=\frac{h_{\text {knurl }, \text { shaft }} \cdot t}{2}-\left(h_{\text {knurl }}-h_{\text {groove }}\left(Q_{H}\right)\right)^{2} * \tan (\alpha / 2)
$$

The adjusted calculation of the areas $A_{0}$ and $A_{1}$ (Figure $4 \mathrm{~b}$ ) leads to a more accurate equivalent plastic strain which allows the numerical modelling of flow stress with the Ludwik approach [13]. With varying hub thickness, counter profile geometry also has to be considered. According to Figure 4, the required hub groove height $h_{\text {groove }}\left(Q_{H}\right)$ can be established by:

$$
h_{\text {groove }}\left(Q_{H}\right)=\left\{\begin{array}{c}
\frac{I_{g e o}}{2} ; Q_{H} \leq 0.65 ; \forall \varphi \\
\frac{I_{g e o}}{2}-\left(\frac{4}{5} Q_{H}+\frac{1}{2}\right) m m ; 0,85>Q_{H} \geq 0.65 ; \varphi<15^{\circ} \\
\frac{I_{g e o}}{2} ; 0,85>Q_{H}>0.55 ; \varphi>60^{\circ}
\end{array}\right.
$$

The height of the knurl $h_{k n u r l}$ results from the groove angle and the pitch:

$$
h_{k n u r l}=\frac{t}{2 \cdot \tan (\alpha / 2)}
$$

Furthermore, the contact area $A_{\text {contact }}$ which influences the contact normal force is calculated by:

$$
A_{\text {contact }}=i \cdot l_{j} \cdot \frac{2 \cdot h_{\text {groove }}\left(Q_{H}\right)}{\cos (\alpha / 2)}
$$

The influence of HDR and SCA is accounted for with the empirical-analytical functions $K_{J}\left(Q_{H}, \varphi\right)$ and $K_{T}\left(Q_{H}, \varphi\right)$, which include expansion of the hub and differentiate between the cutting and forming processes:

$$
\begin{gathered}
K_{J}\left(Q_{H}, \varphi\right)=C_{j 1}+C_{j 2} \cdot Q_{H}+C_{j 3} \cdot \varphi+C_{j 4} \cdot Q_{H}^{2}+C_{j 5} \cdot \varphi^{2}+C_{j 6} \cdot Q_{H} \cdot \varphi \\
\text { with } C_{j 1}=0.7759, C_{j 2}=1.6146, C_{j 3}=-0.0102, \\
C_{j 4}=-2,1717, C_{j 5}=-0.0000145, C_{j 6}=0.00868 \\
K_{T}\left(Q_{H}, \varphi\right)=\frac{C_{T 1}+C_{T 2} \cdot Q_{H}+C_{T 3} \cdot \varphi}{1+C_{T 4} \cdot Q_{H}+C_{T 5} \cdot Q_{H}^{2}+C_{T 6} \cdot \varphi} \\
\text { with } C_{T 1}=0.3017, C_{T 2}=-0.1986, C_{T 3}=0.00158, \\
C_{T 4}=-2.878, C_{T 5}=2.5396, C_{T 6}=0.003107
\end{gathered}
$$

Figure 5 shows the cross-section curves for several HDR depending on SCA according to Equations (13) and (14). Corresponding to the experimental results, a decrease of load can be registered with decreasing SCA (cutting process) and increasing HDR (thin-walled hub).

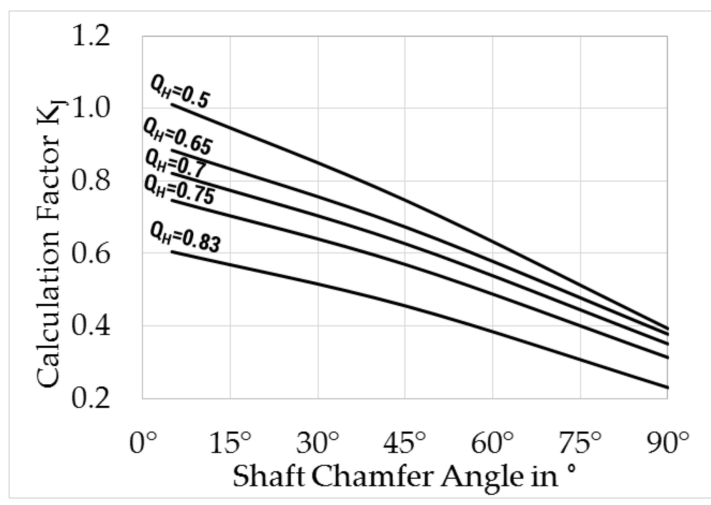

(a)

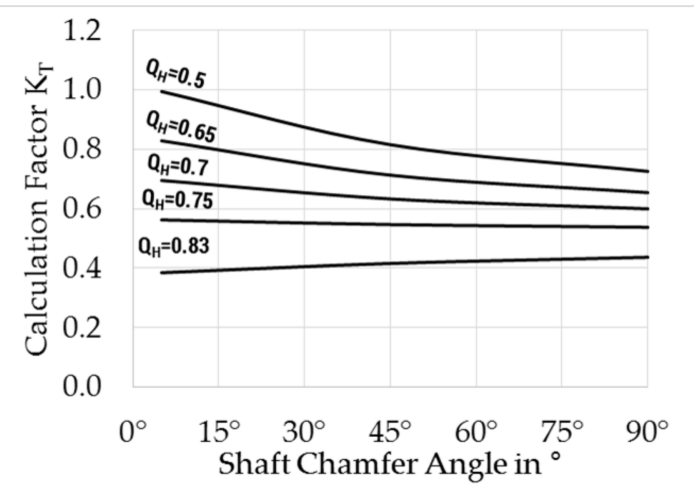

(b)

Figure 5. Factors influencing joining force (a) and maximal torque (b). 


\section{Discussion}

As stated in the Introduction, the goal of the present research was to bridge knowledge gaps in the parameter range of the knurled interference fit. Joining force, as well as torsional load tests, were performed with varying hub-diameter ratios with the cutting and forming joining processes of shafts and hubs.

To conclude the experimental results, the present study supports previous research in this area. A similar influence of shaft chamfer angle was determined as found in [7,8]. As expected, including the new parameters in the known analytical approaches led to calculation errors, which overestimated the load capacity of KIF at higher HDR. Therefore, modifications of Lätzer's approach were made with the goal of minimizing calculation error. Considering the described points, Figure 6 shows a comparison of experimental results between "Lätzer-original" und "Lätzer-modified". Both show a low the deviation of calculated joining force of maximal $7 \%$ in case of forming joining (experiments no. $1-6$, Figure 6a). For cutting connections $\left(\varphi=90^{\circ}\right)$ deviations up to $38 \%$ of Lätzer-original" and $46 \%$ of "Lätzer-modified" are possibly caused by the unknown strain hardening formation on the knurl cutting tip during cutting process.

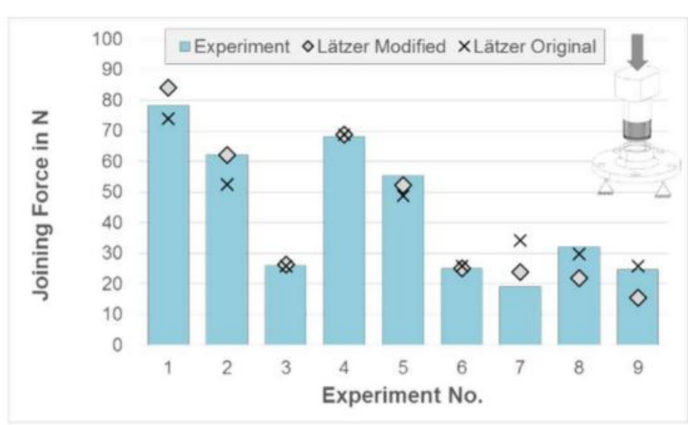

(a)

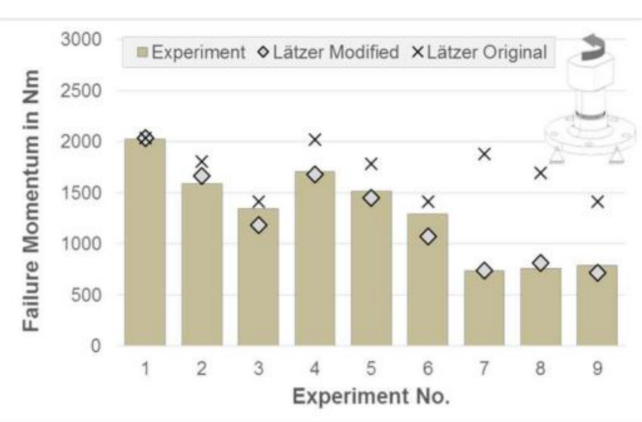

(b)

\begin{tabular}{llllllllll}
\hline Exp. No & 1 & 2 & 3 & 4 & 5 & 6 & 7 & 8 & 9 \\
\hline$\phi$ & $5^{\circ}$ & $45^{\circ}$ & $90^{\circ}$ & $5^{\circ}$ & $45^{\circ}$ & $90^{\circ}$ & $5^{\circ}$ & $45^{\circ}$ & $90^{\circ}$ \\
$Q_{H}$ & 0.50 & 0.50 & 0.50 & 0.65 & 0.65 & 0.65 & 0.83 & 0.83 & 0.83 \\
\hline
\end{tabular}

Figure 6. Comparison of joining force (a) and torque (b) calculations to experiments, $D_{S}=30 \mathrm{~mm}$, $\alpha=103^{\circ}, I_{\text {geo }}=t \cdot 2 / 3, t=1 \mathrm{~mm}, \mu=0.3$.

The accuracy of the new calculation approach is apparent with increasing HDR, where deviation of maximally $17 \%$ and $-3 \%$ on average is reached (Figure $6 \mathrm{~b}$ ). In contrast, the "Lätzer-original" approach reaches deviations up to $155 \%$ (experiment no. 7). Acceptable values for maximal transmitting torque are achieved only for thick-walled hubs (experiment no. 1-3).

The described approach considers the specific specimen geometry. In practice different part geometries can lead to different load capacity. Therefore, a numerical approach for calculation of KIF is investigated additionally [14].

Furthermore, an axial load can be transmitted by the KIF connection due to remaining elastic portion of radial forming of the hub. The transmittable axial loading can be calculated regarding the axial strength described in [6]. The typical axial loads are about $30-45 \%$ of the joining force for cutting process and $60-90 \%$ of the joining force for forming process depending on the geometric interference of the KIF [6]. In dependency of rotational speed of the connection, the maximal transmittable force can differ according to [4]. 


\section{Conclusions}

Innovative design engineers often face novel problems, where missing knowledge leads to underachieving the structure potential. The knurl interference fit has a long record of use in different rotating applications, but the accurate calculation of possible transmittable torque is not fully known.

An example application can be found in modular structures where global structure should stay ductile (lower risk of crack) and contact parts should keep high hardness (wear-resistance). The connection of parts with these different properties are carried out by the KIF. As a result, increased functional integration of the part design is reached.

The results in present paper have been very promising for solving advanced design questions and minimizing experimental costs at the early construction phase of drive systems. Especially, the influence of the strain hardening, which corresponds to an improved material strength, is presently well described for aluminum hubs in dependence of different SCA and different HDR.

Future work concentrates on investigations with more material combinations, extending the analytic approach for more geometry variations. Additionally, a numerical model is built with the goal of investigating an expanded range of parameter. The validity of the present calculation approach for different knurled shapes, such as trapeze or inner knurling, is currently being investigated.

Acknowledgments: This research was made possible by a grant from the German Research Foundation DFG, for which are the authors very grateful.

Author Contributions: Lukas Suchy and Erhard Leidich conceived and designed the experiments; Lukas Suchy performed the experiments; Lukas Suchy and Thoralf Gerstmann analyzed the data; Thoralf Gerstmann and Birgit Awiszus contributed analysis tools; and Lukas Suchy wrote the paper.

Conflicts of Interest: The authors declare no conflict of interest. 


\section{Abbreviations}

\begin{tabular}{|c|c|}
\hline$A_{\text {contact }}$ & contact area \\
\hline$A_{0}$ & reference undeformed area \\
\hline$A_{1}$ & deformed area between knurls \\
\hline$C_{J}$ & joining force correction factor \\
\hline$C_{T}$ & torque correction factor \\
\hline$D_{S}$ & Shaft diameter \\
\hline$D_{i H}$ & Inner diameter of the hub \\
\hline$D_{o H}$ & Outer diameter of the hub \\
\hline$F_{J}$ & joining force of KIF \\
\hline HDR & Hub-diameter-ratio \\
\hline$h_{k n u r l, s h a f t}$ & shaft knurl height \\
\hline$h_{\text {groove }}$ & formed groove height \\
\hline$i$ & number of knurls \\
\hline$K_{Q H}$ & correction factor according to LÄTZER \\
\hline$K_{J}$ & correction factor for joining force \\
\hline$K_{T}$ & correction factor for maximal torque \\
\hline KIF & knurled interference fit \\
\hline$I_{g e o}$ & geometric interference \\
\hline$l_{j}$ & joining length \\
\hline$p$ & contact pressure \\
\hline SCR & shaft chamfer angle \\
\hline$Q_{H}$ & hub-diameter-ratio \\
\hline $\mathrm{t}$ & pitch \\
\hline$T_{\tau_{s}}$ & maximal transmittable torque \\
\hline$\alpha$ & groove angle \\
\hline$\varepsilon_{K I F}^{p l}$ & plastic strain \\
\hline$\tau_{S}$ & shear blasting stress \\
\hline$\varphi$ & shaft chamfer angle \\
\hline
\end{tabular}

\section{References}

1. Deutscher Institut für Normung. DIN 7190-1. Pressverbände-Teil 1: Berechnungsgrundlagen und Gestaltungsregeln für Zylindrische Pressverbände; Deutscher Institut für Normung e.V.: Berlin, Germany, 2017.

2. Wang, X.; Lou, Z.; Wang, X.; Xu, C. A new analytical method for press-fit curve prediction of interference fitting parts. J. Mater. Process. Technol. 2017, 250, 16-24. [CrossRef]

3. Hava, H.; Music, O.; Koç, A.; Karadogan, C.; Bayram, Ç. Analysis of elastic-plastic interference-fit joints. Procedia Eng. 2014, 81, 2030-2035.

4. Kovan, V. Separation frequency analysis of interference fitted hollow shaft-hub connections by finite element method. Adv. Eng. Softw. 2011, 42, 644-648. [CrossRef]

5. Deutscher Institut für Normung. DIN 82. Rändel; Deutscher Institut für Normung e.V.: Berlin, Germany, 1973.

6. Lätzer, M. Untersuchungen zum Füge- und Übertragungsverhalten Torsionsbelasteter Stahl-AluminiumRändelpressverbindungen. Ph.D. Thesis, Technische Universität Chemnitz, Chemnitz, Germany, 2015.

7. Lätzer, M.; Leidich, E.; Kleditzsch, S.; Awiszus, B. Untersuchungen zum Übertragungsverhalten von Rändelpressverbänden aus Stahl-Aluminium. In Untersuchungen zum Übertragungsverhalten von Rändelpressverbänden aus Stahl-Aluminium; Forschung im Ingenieurwesen; Springer: Berlin, Germany, 2015; Volume 79, pp. 41-56.

8. Bader, M. Das Übertragungsverhalten von Pressverbänden und die Daraus Abgeleitete Optimierung Einer Formschlüssigen Welle-Nabe-Verbindung. Ph.D. Dissertation, Technische Universität Graz, Graz, Austria, 2009.

9. Hirota, K.; Kitamura, K.; Ukai, Y.; Matsunaga, K. Mechanical joining of shaft and holed disc in rotational and axial directions. Procedia Eng. 2017, 207, 980-985. [CrossRef]

10. International Organization for Standardization. ISO 6892-1. Metallic Materials-Tensile Testing-Part 1: Method of Test at Room Temperature; ISO: Geneva, Switzerland, 2017. 
11. International Organization for Standardization. ISO 6507-1. Metallic Materials_Vickers Hardness Test-Part 1: Test Method; ISO: Geneva, Switzerland, 2005.

12. Reiß, F.; Gräfensteiner, M. Transferability of Static Friction Coefficients; FVV Final Report 1148; Forschungsvereinigung Verbrennungsmotoren e.V.: Chemnitz, Germany, 2018.

13. Ludwik, P. Elemente der Technologischen Mechanik; Springer: Berlin, Germany, 1909.

14. Gerstmann, T.; Awiszus, B.; Suchý, L.; Leidich, E. Numerische Analyse des Montage- und Übertragungsverhaltens von Rändelpressverbänden. In VDI-Berichte 2287; VDI Wissensforum GmbH: Karlsruhe, Germany, 2016.

2018 by the authors. Licensee MDPI, Basel, Switzerland. This article is an open access article distributed under the terms and conditions of the Creative Commons Attribution (CC BY) license (http://creativecommons.org/licenses/by/4.0/). 